\title{
Demystifying EMERGENCE
}

\author{
DAVID YATES \\ Centro de Filosofia, Universidade de Lisboa
}

\begin{abstract}
Are the special sciences autonomous from physics? Those who say they are need to explain how dependent special science properties could feature in irreducible causal explanations, but that's no easy task. The demands of a broadly physicalist worldview require that such properties are not only dependent on the physical, but also physically realized. Realized properties are derivative, so it's natural to suppose that they have derivative causal powers. Correspondingly, philosophical orthodoxy has it that if we want special science properties to bestow genuinely new causal powers, we must reject physical realization and embrace a form of emergentism, in which such properties arise from the physical by mysterious brute determination. In this paper, I argue that contrary to this orthodoxy, there are physically realized properties that bestow new causal powers in relation to their realizers. The key to my proposal is to reject causal-functional accounts of realization and embrace a broader account that allows for the realization of shapes and patterns. Unlike functional properties, such properties are defined by qualitative, non-causal specifications, so realizing them does not consist in bestowing causal powers. This, I argue, allows for causal novelty of the strongest kind. I argue that the molecular geometry of $\mathrm{H}_{2} \mathrm{O}-\mathrm{a}$ qualitative, multiply realizable property-plays an irreducible role in explaining its dipole moment, and thereby bestows novel powers. On my proposal, special science properties can have the kind of causal novelty traditionally associated with strong emergence, without any of the mystery.
\end{abstract}

ccording to the layered model, our world is naturally divided into a hier-
archy of levels, with basic physics at the bottom. Although higher-level
properties and particulars are ultimately dependent upon and determined by
basic physics, they are the subject matter of autonomous sciences. What does
the autonomy of the so-called special sciences - chemistry, biology, neuroscience,
psychology - consist in? According to a longstanding tradition, special science
autonomy requires that the relevant higher-level properties feature in laws that

Contact: David Yates < david.yates@campus.ul.pt > 
provide genuine causal explanations that are not available from a purely basic physical perspective (Fodor 1997: 149-150). Assuming that in general, properties are causally relevant by dint of the causal powers they bestow, the most obvious way for special sciences to secure autonomy is for dependent special science properties to bestow novel causal powers relative to the basic physical properties upon which they depend. However, the demands of a broadly physicalist worldview require that these properties are not only dependent on basic physics, but also in some appropriate sense physically realized (Horgan 1993; Wilson 1999; 2015). Because realized properties are derivative, and in some sense nothing over and above their realizers, it's notoriously difficult to see how they could bestow causal powers that their realizers do not, whence a dilemma: it seems we must either give up autonomy, and with it the layered model; or give up physicalism, and replace physical realization with a mysterious emergence that allows dependent properties to bestow novel powers.

This dilemma is at the heart of the Fodor-Kim debate on the special sciences (Fodor 1974; 1997; Kim 1992; see also Block 1997). Kim raises two key challenges to Fodor's physicalist layered ontology, based on a causal inheritance principle, according to which realized property-instances inherit all their causal powers from their realizers. This principle entails that: (1) the causal powers of a realized property-instance are a subset of the powers of its realizer on that occasion. ${ }^{1}$ It follows that realized properties cannot bestow any causal powers their realizers do not, and on this basis Kim argues that they are causally redundant. Kim often assumes in addition that realized property-instances inherit all the causal powers of their realizers, so that: (2) the causal powers of a realized propertyinstance are identical to the powers of its realizer on that occasion. ${ }^{2}$ Kim argues that this renders special science properties not only causally redundant, but also as causally heterogeneous as their basic physical realization bases, and therefore unsuitable for framing laws. ${ }^{3}$

Defenders of the layered model typically accept the causal inheritance principle, and argue that despite not bestowing novel powers, special science properties nonetheless exhibit enough causal novelty to be non-redundant, and enough causal unity to be nomic. According to the proper subset strategy, for instance, realized properties inherit their causal powers, but inherit only some of the powers of their realizers, which allows for both nomic unity and a limited form of

1. This is how Kim (1998: 54) states the inheritance principle.

2. See for instance Kim (1993: 18).

3. Fodor (1997) disagrees that heterogeneity of the realization base precludes special science laws; Block (1997) offers support for Fodor on this point, arguing that where design or natural selection is at work, special science properties are projectible in relation to their selected effects despite differences in realization. These matters are beyond the scope of this paper. 
causal novelty (Wilson 1999; Shoemaker 2001).4 Such strategies promise the kind of causal-explanatory novelty required for special science autonomy without novel causal powers, but whether or not they deliver is a matter of considerable controversy. What is uncontroversial is that physical realization rules out novel causal powers, so that the only way to defend the layered model is to give an account of the causal novelty of special science properties that is consistent with their having only inherited causal powers.

In this paper, I offer a groundwork for a physicalist form of emergentism about the special sciences, based on rejecting the causal inheritance principle, and according to which some realized properties bestow causal powers their realizers do not. I'll refer to any property $\mathrm{F}$ whose bearers have at least one causal power in virtue of $\mathrm{F}$, and no other property (except in cases where that property inherits F's powers), as causally fundamental. 5 I'll use the term 'basic physical' for unrealized, independent causally fundamental properties such as electric charge. According to the orthodoxy sketched above, only basic physical properties are casually fundamental, since causal fundamentality for dependent properties precludes physical realization, and so requires the kind of mysterious brute determination endorsed by the British emergentists. ${ }^{6}$ My central aim here is to argue against this orthodoxy. I shall argue that the molecular geometry of $\mathrm{H}_{2} \mathrm{O}$ is a multiply realizable property that plays an irreducible role in explaining the dipole moment of the molecule, and that it thereby bestows causal powers its basic physical realizers do not. Through this, I aim to show that physical realization is consistent with causal fundamentality, making room for a position on the special sciences that has all the important features of traditional emergentism except the mystery. ${ }^{7}$

As we'll see, the key to my proposal is the claim that at least some special science properties are, in a sense to be clarified presently, qualitatively-as opposed to functionally - realized. Functional properties are causally individuated, and to instantiate one is to have its defining causal powers; correspondingly, to realize one is to bestow those powers. Functional realization in effect derives special science properties from their realizers by means of derivative causal powers, and the

4. Although Fodor doesn't often talk in terms of causal powers, his (1997) model of special science autonomy is functionalist, and as Wilson (2015) argues, functionalism can plausibly be seen as a version of the proper subset strategy.

5. I do not claim that causal novelty is the only way for a property to secure fundamentality, hence my appeal to causal fundamentality as opposed to fundamentality simpliciter.

6. E.g., Alexander (1920), Morgan (1923), Broad (1925). It isn't entirely clear that Alexander posits brute determination in order to explain causal novelty, but it is plausible; see McLaughlin (1992: 66-67).

7. Readers for whom brute determination is an essential component of emergence will need to find an alternative term for the position defended here. I'll say more about the traditional role of brute determination in Sections 1-2. 
causal inheritance principle is a natural consequence. By contrast, qualitatively realized properties are defined by non-causal specifications, and their realization is not a matter of bestowing the right causal powers. Properties such as molecular geometry are causally fundamental, I shall argue, because their bearers have certain causal powers in virtue of meeting their defining specifications, but not in virtue of the realizer properties in virtue of which they meet those specifications on a given occasion.

My talk of causal powers should not be mistaken for commitment to a powers ontology, in which basic physical properties are treated as individuated by the causal powers they bestow. ${ }^{8}$ I hold that things are thus-and-so empowered in virtue of their properties, where to be thus-and-so empowered is to be such as to enter into a characteristic range of causal interactions with other empowered particulars under certain circumstances. I leave open the nature and strength of the relation between basic physical properties and the powers they bestow, thereby remaining neutral as to whether any such properties are causally individuated. Powers so conceived manifest when the appropriate circumstances obtain, and their bearers behave in the appropriate ways; causation may then be seen as the coming together of empowered particulars, resulting in whatever their powers are powers to do. I'm also neutral as to whether empowered particulars may fail to manifest their powers when the relevant circumstances obtain. ${ }^{9}$ The sense in which properties bestow causal powers is simply that they determine, or contribute to determining, how their bearers are disposed to behave under a range of circumstances. A property that makes a novel contribution in this regard bestows a novel power.

The plan of the paper is as follows. In Section 1, I give a more precise account of emergence in order to clarify what it is I aim to demystify. In Section 2, I distinguish functional from qualitative realization, and argue that geometric properties are multiply qualitatively realized by the basic physical properties of their bearers. In Section 3, I discuss the chemical explanation of the dipole moment of water, and argue that $\mathrm{H}_{2} \mathrm{O}$ molecules have certain causal powers in virtue of their molecular geometry; and in Section 4 I argue that they possess these powers solely in virtue of their molecular geometry. In Section 5 I consider an objection to the proposed model based on the prima facie transitivity of the 'in virtue of' relation invoked once between basic physics and molecular geometry, then again between molecular geometry and causal powers; and I conclude in

8. Variants of such ontologies are defended in Shoemaker (1980), Heil (2003), Molnar (2003), and Bird (2007).

9. Mumford and Anjum (2011) argue that power manifestation isn't metaphysically necessary, because any power can be prevented from manifesting by the addition of further empowered particulars, whereas metaphysical necessitation is monotonic. Heil (2016) argues that these aren't cases in which the original power fails to manifest, but ones in which a new network of powers manifests exactly as it must. I needn't take sides here. 
Section 6 by considering the prospects for my emergentism as the ground of special science autonomy.

\section{Emergence and Causal Novelty}

Jessica Wilson's distinction between strong and weak metaphysical emergence offers a useful framework within which to discuss dependent causal novelty (Wilson 2015: 353-363; see also Wilson 1999; 2005; 2011).

Strong: Token higher-level feature $\mathrm{F}$ is strongly metaphysically emergent from token lower-level feature P on a given occasion iff: (i) F synchronically depends on P on that occasion; and (ii) $\mathrm{F}$ has at least one token power not identical with any token power of $\mathrm{P}$ on that occasion.

Weak: $\quad$ Token higher-level feature F is weakly metaphysically emergent from token lower-level feature $P$ on a given occasion iff: (i) F synchronically depends on P on that occasion; and (ii) F has a non-empty proper subset of the token powers had by P on that occasion.

As they stand, these definitions aren't quite what we need for present purposes. For one thing, Wilson speaks in terms of token properties having causal powers, whereas I prefer to speak in terms of properties bestowing powers. More seriously, Wilson's (Strong) might be taken to imply that the hardness of a diamond, for instance, is strongly emergent. Suppose one held, with Carl Gillett (2002), that hardness is not a property of the individual carbon atoms that make up a diamond, or of the tetrahedral lattice structures of those atoms when arranged diamond-wise. Rather, hardness is a property of particular diamonds. The hardness of a diamond is realized by basic physical properties in the sense that the diamond possesses the powers definitive of hardness in virtue of the powers bestowed upon its constituent atoms by those properties (Gillett 2002: 318-320). If this is correct, then it seems - at least on the assumption that property-instances literally have causal powers - that an instance of the property of being a diamond will have several token powers, viz. those definitive of hardness, that are not identical to any token powers of its basic physical realizers. Because I'm sympathetic to Gillett's theory of realization - I'll adopt a modified version of it in Section 2-I need to reformulate Wilson's distinction accordingly: ${ }^{10}$

10. The parenthetical clauses are for consistency with the account of realization adopted in Section 2. I leave 'in virtue of' as a primitive for now, but I'll have more to say about it in Section 5. 
Strong': $\quad$ Token higher-level feature F of $x$ is strongly metaphysically emergent from token lower-level features $\mathrm{P}_{1}, \ldots, \mathrm{P}_{n}$ of $x$ (or its proper parts) on a given occasion iff: (i) $\mathrm{F}$ synchronically depends on $\mathrm{P}_{1}, \ldots, \mathrm{P}_{n}$ on that occasion; and (ii) $x$ has at least one token power in virtue of $\mathrm{F}$ but not in virtue of $\mathrm{P}_{1}, \ldots, \mathrm{P}_{n}$ on that occasion.

Weak': $\quad$ Token higher-level feature $\mathrm{F}$ of $x$ is weakly metaphysically emergent from token lower-level features $\mathrm{P}_{1}, \ldots, \mathrm{P}_{n}$ of $x$ (or its proper parts) on a given occasion iff: (i) $\mathrm{F}$ synchronically depends on $\mathrm{P}_{1}, \ldots, \mathrm{P}_{n}$ on that occasion; and (ii) $x$ has a non-empty proper subset of the powers it has in virtue of $\mathrm{P}_{1}$, $\ldots, \mathrm{P}_{n}$ in virtue of $\mathrm{F}$ on that occasion.

Given (Strong'), the hardness of a diamond is not strongly emergent, for it is clearly in virtue of its lattice structure that a diamond is hard. ${ }^{11}$ As far as I can tell, it's universally agreed that strong emergence is not consistent with physical realization, and for that reason it's not typical to appeal to it as an ordering relation in a layered ontology. Weak emergence, by contrast, is clearly consistent with physical realization, and offers an elegant way to rebut Kim's argument that special science properties are causally heterogeneous. A weak emergentist can accept that $\mathrm{F}$ inherits its powers from its realizers, but deny that $\mathrm{F}$ inherits all of those powers, and can then account for F's nomic unity by claiming that all instances of $\mathrm{F}$ bestow the same non-empty proper subset of the powers of their realizers. ${ }^{12}$

Whether weak emergence could underpin a robustly layered world, however, is moot. True, in bestowing only a proper subset of $\mathrm{P}_{1}, \ldots, \mathrm{P}_{n}{ }^{\prime} \mathrm{s}$ powers, $\mathrm{F}$ does something that $\mathrm{P}_{1}, \ldots, \mathrm{P}_{n}$ cannot do; however, $\mathrm{F}$ also does something that $\mathrm{P}_{1}, \ldots, \mathrm{P}_{n}$ must do, viz. bestowing a proper subset of $\mathrm{P}_{1}, \ldots, \mathrm{P}_{n}$ 's powers. Weakly emergent properties may have novel causal profiles, but they don't bestow novel powers. Now according to received wisdom, physically realized properties are at most weakly emergent, ${ }^{13}$ so there's a principled limit to their novelty. Against this backdrop, it's all too easy for reductionists to argue that the while the world

11. It may be that Wilson's intention is that a token feature 'has' a given power only in the non-literal sense that it is an instance of a property in virtue of which its bearer literally has that power, in which case the hardness of a given diamond does come out as a power that its token realizers 'have' on that occasion. Even so, it remains useful to reformulate the distinction so that this is explicit.

12. Wilson (2015) argues at length that all attempts to square special science autonomy with the physical realization of special science properties are (at least tacitly) forms of weak emergence. An apparent exception to this claim, which Wilson doesn't discuss, is List and Menzies (2010), of which more in Section 4.

13. I'll have more to say about the reasons for this consensus in Section 2. 
may be conceptually layered, it is ontologically flat. By contrast, strongly emergent properties, qua causally fundamental, could without question underpin a robustly layered world, but only at the cost of giving up on physical realization, which is a price not worth paying. What the layered model arguably needs is strong emergence, but-so the familiar story goes-only weak emergence is on the table.

Novel causal powers in the sense given by (Strong') are not the only way of characterising strong emergence. Some say strongly emergent properties generate new forces in addition to those generated by their physical bases, or - if this is different - that they are governed by sui generis causal laws (Alexander 1920; Broad 1925); others that they have effects that are not additive sums of the effects of their base properties (Morgan 1923); and others that they exert a downward causal influence on the basic physical domain (Morgan 1923; Broad 1925; Sperry 1975). It is also often said that strongly emergent properties are not deducible from basic physics - not even in principle-typically due to some prior metaphysical theory, such as the ones just mentioned (Alexander 1920; Broad 1925). I shall argue in what follows that molecular geometry is strongly emergent according to (Strong'), in such a way that: (a) it does not generate new forces, nor is it governed by sui generis causal laws; (b) its effects are not an additive sum of the effects of its basic physical realizers; (c) this is a case of downward causation; (d) despite being strongly emergent, molecular geometry is deducible from basic physics. ${ }^{14}$

\section{Functional versus Qualitative Realization}

Realized properties - unlike traditional strongly emergent properties-are derivative, in the following sense. Take the actual fundamental entities to be those that are necessary and sufficient for God to duplicate in order to create a duplicate simpliciter of our world. Everything else - the derivative entities-(S)He gets for free. ${ }^{15}$ On this view, derivative properties are, in David Armstrong's (1997: 1213) words, a metaphysical free lunch, "no addition of being" compared to their realizers. Because they are derived from their realizers, it's natural to suppose that the powers of realized properties must likewise be derived from the powers of their realizers. Intuitively, properties that have the kind of causal novelty defined by (Strong') can't be derivative, hence can't be realized. The main accounts of realization in the literature encode this intuitive constraint by defining the realization relation in terms of derivative causal powers. Consider first accounts of

14. I defend claims (a)-(d) at the end of Section 4.

15. For more on this characterisation of the derivative, see Barnes (2012). 
realization on which the realized property is construed as a second-order functional property: $\mathrm{F}=$ the property of having some other property with causal role $\mathrm{R}$; and P realizes F iff P fills R. ${ }^{16}$ This conception of realization is behind Kim's commitment to the causal inheritance principle, according to which the powers of a given instance of $\mathrm{F}$ are inherited from its realizer on that occasion. Clearly, $\mathrm{F}$ can't causally outstrip $P$, and is at most weakly emergent, depending on whether F inherits all of P's causal powers, or just those relevant to filling $R$. If the latter, F is weakly emergent according to both (Weak) and (Weak').

It isn't just second-order functionalists who think that the causal powers of realized properties are derivative. Consider Gillett's (2002; 2003) dimensioned theory of realization, according to which:

Property instance(s) $\mathrm{P}_{1}, \ldots, \mathrm{P}_{n}$ realize an instance of a property $\mathrm{F}$, in an individual $x$, iff $x$ has powers that are individuative of an instance of $\mathrm{F}$ in virtue of the powers contributed by $\mathrm{P}_{1}, \ldots, \mathrm{P}_{n}$ to $x$ or $x^{\prime}$ s constituents, but not vice-versa.

In Gillett's account, $\mathrm{F}$ is again construed as a causally individuated property, but not as a second-order property. The account is consistent with Kim's causal inheritance principle, but doesn't require it, since Gillett holds that there are cases - such as the hardness of a diamond, discussed in Section 1-in which the powers that individuate $\mathrm{F}$ are not straightforwardly powers bestowed by $\mathrm{P}_{1}$, $\ldots, \mathrm{P}_{n}$, because they are not instantiated by $x^{\prime}$ s basic physical constituents at all. This is what leads Gillett to deny that functional properties are second-order, for second-order properties and their first-order realizers, he argues, are instantiated in the same individual. On the dimensioned theory, however, it remains true that $\mathrm{F}^{\prime}$ s causal powers are inherited from $\mathrm{P}_{1}, \ldots, \mathrm{P}_{n}$ in the weaker sense that any causal powers $x$ has in virtue of $\mathrm{F}$, it ultimately has in virtue of $\mathrm{P}_{1}, \ldots, \mathrm{P}_{n}$. Once more, realized properties are at most weakly emergent, depending on whether $x$ has any powers in virtue of $\mathrm{P}_{1}, \ldots, \mathrm{P}_{n}$ but not in virtue of $\mathrm{F}$. If it does, then $\mathrm{F}$ will be weakly emergent according to (Weak').

It isn't just functionalists who treat realization in terms of derivative causal powers. Consider first Sydney Shoemaker's version of the subset theory of realization:

Property $\mathrm{X}$ realizes property $\mathrm{Y}$ just in case the powers bestowed by $\mathrm{Y}$ are a subset of the powers bestowed by $X$ (and $X$ is not a conjunctive property having $\mathrm{Y}$ as a conjunct). (2001: 78)

16. See Kim (1992) for more on this conception of realization, and its problems. 
It's immediately clear that on this theory, $\mathrm{Y}$ cannot be strongly emergent, for all its causal powers are bestowed by $X$. Whether $Y$ is weakly emergent or not emergent at all depends on which subset of $X^{\prime}$ 's powers it bestows. This in turn depends on whether $\mathrm{Y}$ is multiply realized, in which case its powers are a proper subset of X's. In the light of Shoemaker's (1980) causal theory of properties, it's natural to interpret his theory of realization in terms of parthood: if we identify properties $X$ and $Y$ with sets of powers, then $X$ realizes $Y$ iff $X$ is part of $Y .{ }^{17}$ However, Shoemaker explicitly denies that his theory of realization depends on the causal theory of properties. Having originally proposed the subset account as a theory of realization specifically for functionalists, in which case $\mathrm{Y}$ is treated as a functional property, he later recants, suggesting that the theory doesn't even require $Y$ to be causally individuated. ${ }^{18}$

On Wilson's (1999; 2011; 2015) version of the subset theory, a multiply realized property bestows a proper subset of the powers of its realizer, and is weakly emergent according to (Weak). ${ }^{19}$ Strictly speaking, Wilson doesn't offer the proper subset account as a theory of realization, but as a necessary and sufficient condition that theories of realization must meet if they are to be adequate to the needs of non-reductive physicalists. A theory of realization, for Wilson, delivers physically acceptable, irreducible realized properties iff that theory entails that the powers of a realized property-instance are a proper subset of the powers of its realizer on that occasion - whether or not the realized property is functional. ${ }^{20}$ On both Shoemaker's and Wilson's accounts, then, realization respects the causal inheritance principle, and realized properties are at most weakly emergent. In Wilson's case, weak emergence is taken as a necessary and sufficient condition for a theory of realization to be suitable for framing non-reductive physicalism.

For my part, I think that both Shoemaker and Wilson are right to adopt accounts of realization that don't require realized properties to be causally individuated, but wrong to hold on to the causal inheritance principle. The inheritance principle is a consequence of functionalism, according to which realized properties are individuated by causal roles and realizing them is a matter of filling those roles. To embrace it as a definition of or constraint upon realization while denying that special science properties are functional, however, is to throw out the baby but keep the bathwater. I agree with Wilson that weak emergence is

17. If $\mathrm{Y}$ is multiply realized, then of course $\mathrm{X}$ is a proper part of $\mathrm{Y}$.

18. Shoemaker claims that his theory of realization depends "only on the weaker thesis that each property is individuated by a causal profile in the sense that it and it alone has that profile in the actual world and worlds nomologically like it" (2007: 142).

19. Wilson explicitly treats realization in terms of (Weak) in her (2015).

20. See in particular Wilson (2011). Wilson is clear from the outset that her theory doesn't require a commitment to functionalism, and points to this feature as an advantage over Shoemaker's (2001) position. 
a sufficient condition for physical acceptability and accept that it offers a limited form of causal novelty. ${ }^{21}$ As I noted in Section 1, I doubt that weak emergence offers enough causal novelty to underpin a layered ontology, but I needn't argue for that claim here. Instead, I'll focus on establishing that weak emergence is not necessary for physical acceptability, because some realized properties bestow causal powers their realizers do not, and are thus strongly emergent.

Extant accounts of realization have it in common that the causal powers of realized properties are inherited from their realizers. Because this constraint is definitive of functionalism, I'll refer to such theories of realization as functionalist, whether or not they embrace the causal individuation of realized properties. Functional realization, broadly construed, consists in bestowing casual powers, and requires that the powers of the realized property are derived from those of its realizers. If functional realization were the only way of realizing special science properties, then strong emergentism about the special sciences would indeed preclude physical acceptability, and require us to embrace mysterious, brute inter-level determination relations with "natural piety" (Alexander 1920: 46-47). However, not all realized properties are functionally realized.

By way of illustration, let us consider the sphericality of material bodies. In Cartesian co-ordinates, we may define the property of being a sphere of radius $R$, centred at $\left(x_{0}, y_{0}, z_{0}\right)$, as the property of being an $X$ such that all points $(x, y, z)$ that lie at X's outer boundary satisfy the formula: $\left(x-x_{0}\right)^{2}+\left(y-y_{0}\right)^{2}+\left(z-z_{0}\right)^{2}=R^{2}$. Actual spheres are only approximately spherical, but that needn't concern us here. Complex spherical bodies (more or less) satisfy the above formula in virtue of the properties and relations of their proper parts. ${ }^{22}$ To be spherical, bodies need proper parts with some intrinsic basic physical properties or other, but given suitable basic physical particulars, all we need to do to make a sphere of radius $R$ is arrange them so that they compose a body that satisfies the formula. In general, to have a geometric property is to satisfy a certain mathematical formula; and things that have the property in question satisfy the defining formula in virtue of the properties and relations of their basic physical proper parts.

I'll describe the formulae that define geometric properties as specifications of those properties, but I don't claim that all specifications are mathematical formulae, or that all the properties they specify are geometric. Now crucially, because sphericality has a non-causal specification, its realizers do not realize it by bestowing causal powers. I'll refer to realized properties with non-causal specifications as qualitatively realized. We must be careful to distinguish properties such as

21. I think this holds true whether we understand weak emergence in terms or (Weak) or (Weak').

22. I treat sphericality as mathematically defined, but this is not to say that sphericality is an abstract or mathematical property. As I see it, sphericality is among those broadly physical properties whose essential natures can be described by means of abstract mathematical formulae. 
the electrostatic bonds that are responsible for the diachronic stability of a solid metal sphere's shape, from the properties that synchronically realize its shape. While the former realize the rigidity of such a sphere by means of the causal powers they bestow, the latter realize its sphericality at a given time by being properties and relations in virtue of which it meets the relevant specification at that time. I adopt the following general account of realization:

Property instance(s) $\mathrm{P}_{1}, \ldots, \mathrm{P}_{n}$ realize a property-instance $\mathrm{F}_{\phi}(x)$ iff (i) $x$ or its proper parts possess $\mathrm{P}_{1}, \ldots, \mathrm{P}_{n}$ in some combination; and (ii) $x$ meets the specification $\phi$ definitive of $\mathrm{F}_{\phi}$ in virtue of (i), but not vice-versa. ${ }^{23}$

The above account allows for functional realization-simply let $\phi$ be a causal role specification and $\mathrm{F}_{\phi}$ be a property individuated by that role. However, for full generality we may allow $\phi$ to be any proposition that is the specification a realizable property. ${ }^{24}$ The account is broad enough to allow that not only the dispositional properties of diamonds, but also their geometric shapes, are realized by their basic physical properties and relations. Geometric properties are also multiply realized in basic physics. Spheres can be made of wood, iron, glass, steel, water, light; the proper parts of a given sphere need not be of the same kind; and there are many possible distinct sphere-wise arrangements of the same proper parts. Readers familiar with Lawrence Shapiro's views on realization may however be inclined to doubt this:

Steel and aluminium are not different realizations of a waiter's corkscrew because, relative to the properties that make them suitable for removing corks, they are identical. (2000: 644)

Shapiro's idea is that both the steel and aluminium corkscrews are composed of rigid metal parts of the same shape and structure, all of which are broadly physical properties, and at this level of specification the property of being a corkscrew is uniformly realized in each case. However, the different basic physical properties of the metals that compose each corkscrew are the properties that ultimately realize the dispositional and geometric properties in virtue of which each mechanism functions as a corkscrew, for instance rigidity, shape, and structure. The corkscrews are identical "relative to the properties that make them suitable for removing corks" only if we focus solely on properties such as the

23. This account owes much to Gillett's, discussed above.

24. Note that Melnyk (2003) endorses an account of realization that allows for non-causally individuated properties to be realized, but doesn't draw anything like the conclusions from that view that I do. I make no attempt at demarcating propositions that do, from those that do not, specify realizable properties. 
rigidity or shape of the components, or the structure of the mechanism, abstracting away from the differences in their realization. ${ }^{25}$ It is unduly restrictive to insist that the two corkscrews are uniform realizations of the waiter's corkscrew simply because their components have the same shapes, or because they have the same mechanistic structure. In any case, the kind of variability in realization that obtains between the two corkscrews is all I claim for qualitatively realized properties.

Functionally realized properties, as we've seen, are at most weakly emergent, but qualitatively realized properties don't share this principled limitation. The reason for this is that the bearer of a qualitatively realized property can have certain causal powers: (i) in virtue of meeting the defining specification, but (ii) not in virtue of basic physical properties and relations in virtue of which it meets that specification. It follows that qualitative realization is consistent with strong emergence as defined in (Strong'). That makes qualitatively realized properties much better candidates for securing the autonomy of the special sciences than their functionally realized counterparts. Qualitative realization has the resources to demystify emergence, I shall argue, because it makes it possible for dependent properties to be causally fundamental without the need for brute determination.

Before proceeding, let me pause to distinguish the current project from a recent demystification attempt due to Elizabeth Barnes (2012). ${ }^{26}$ Barnes defends a meta-ontological framework in which every entity is either absolutely fundamental or derivative, and nothing is both. Barnes's proposal is that we can demystify emergence by interpreting it as the claim that there are dependent fundamental entities. What is novel in Barnes's approach is the idea that many of the problems with emergentism stem from trying to make sense of it within a layered ontology in which the levels are ordered by relative fundamentality, with the bottom level-basic physics - alone qualifying as absolutely fundamental. On this model, given that basic physical entities fully compose all others, strong emergence requires downward causation from less fundamental higher level properties to the absolutely fundamental physical domain, and this in turn raises doubts about the coherence of strong emergence.

Barnes suggests that strong emergentists' problems with downward causation stem from the natural supposition that all causal relations can be fully explained in terms of the absolutely fundamental. If basic physics alone is absolutely fundamental, then it seems it ought to be causally closed, but strong emergence violates the causal closure of basic physics. In Barnes's alternative framework, the commitment is not to the causal closure of the basic physical, but

25. Similar points are made in Gillett (2003).

26. I lack the space to do full justice to Barnes's paper, and focus solely on her claim that making certain meta-ontological moves suffices to demystify the causal novelty of strongly emergent properties. 
to the causal closure of the fundamental, which may include strongly emergent non-basic properties. On the assumption that all genuinely causally novel entities are fundamental, the causal closure of the fundamental is a priori, because the class of fundamental entities is bound to include a minimally sufficient basis for explaining everything that happens. In a layered ontology, as Barnes sees it, emergent properties are less fundamental than basic physical properties, despite having just the same kind of causal novelty. On Barnes's view, dependent causally fundamental properties and basic physical properties are equifundamental.

Does this suffice to demystify emergence? Yes and no. In Broad's emergentism, for instance, emergent properties such as the chemical bond are both dependent and causally novel, thereby violating the causal closure of the basic physical. This is reflected in Wilson's (Strong) and my (Strong'), which characterize strong emergence in terms of dependent properties with new causal powers, which entails that they are both dependent and fundamental, assuming causal fundamentality is sufficient for fundamentality simpliciter. If demystifying emergence were as simple as allowing for causally fundamental dependent properties, and hence rejecting the causal closure of the basic physical, then there wouldn't be anything mysterious about Broad's emergentism. However, Broad needed special trans-ordinal laws to ground the dependence of emergent properties on basic physics, and their novel powers, which is in itself mysterious.

In sum, my demystification project takes off where Barnes's ends: she holds that the key to emergence is causally fundamental dependent properties, which in turn requires us to abandon the idea that the basic level is causally closed, and I agree. Indeed, the position I shall argue for in this paper violates the causal closure of basic physics. ${ }^{27}$ However, while there is no room in Barnes's metaontological framework to question how dependent properties could be causally fundamental given the causal closure of basic physics, there's plenty of room to question how they could be causally fundamental at all. As I said, according to Barnes nothing can be both fundamental and derivative; realized properties could not therefore be causally fundamental, on her account. That places her squarely in the tradition discussed above, according to which derivative properties have derivative causal powers. If she were defending emergentism of the kind she takes her meta-ontology to demystify, Barnes would presumably need to posit special emergence laws or brute dependency relations of some kind, just as Broad did, and that seems to me to take us back into the realm of the mysterious. In any case, my strategy here will be to argue that derivative properties can, after all, be causally fundamental-provided they are qualitatively, rather than functionally, realized.

27. I'll return to this issue in Section 4 . 


\section{The Causal Relevance of Molecular Geometry}

It's uncontroversial that molecules possess causal powers in virtue of their molecular structure. A case in point is the dipole moment of $\mathrm{H}_{2} \mathrm{O}$, which is responsible, inter alia, for hydrogen bonding in water, which in turn is responsible for water being a liquid at room temperature and ratm pressure. The dipole moment itself is explained in terms of the geometry of the $\mathrm{H}_{2} \mathrm{O}$ molecule, which is therefore causally relevant. What is less clear, and hitherto unappreciated, is that molecular geometry cannot be eliminated, even in principle, from the explanation. I'll get to that in Section 4; in this section, my purpose is to clarify the role of molecular geometry in explaining the dipole moment of $\mathrm{H}_{2} \mathrm{O}$, and the causal powers it bestows as a result.

Water molecules are composed of two hydrogen atoms covalently bonded to a single oxygen atom. In each of these covalent bonds one of the $\mathrm{O}$ atom's six valence electrons is shared with the $\mathrm{H}$ atom's lone electron. The $\mathrm{O}$ atom in an $\mathrm{O}-\mathrm{H}$ bond attracts these electrons more than the $\mathrm{H}$ atom, due to its greater electronegativity - the $\mathrm{O}$ atom has eight positively charged protons, while each $\mathrm{H}$ atom has just one. Each of the two bonds is therefore polar, in that each is more negative to towards the $\mathrm{O}$ end. This polarity is modelled as the separation of two partial charges, $\delta+$ and $\delta$-, separated by a distance $\mathrm{B}$, the $\mathrm{O}-\mathrm{H}$ bond length. The separation of two equal and opposite charges of magnitude $\delta$ results in a dipole moment $\mu_{\mathrm{OH}}$, which is a vector quantity whose magnitude is given by $\mu_{\mathrm{OH}}=\delta \mathrm{B}$, directed by convention from $\delta+$ to $\delta$-. Now in an $\mathrm{H}_{2} \mathrm{O}$ molecule, there are also two lone pairs of valence electrons not used up in covalent bond formation. We can predict the bond angles in the $\mathrm{H}_{2} \mathrm{O}$ molecule by using the valence shell electron-pair repulsion (VSEPR) model. The idea is to treat the bonds and lone pairs as located on the surface of a sphere centred on the central atom, and assume that they will try to get as far away from each other as possible due to mutual repulsion between the electron pairs in the bonds and the lone pairs. We add the number of atoms bonded to the central atom to the number of its lone pairs, to get the steric number of the molecule. The $\mathrm{H}_{2} \mathrm{O}$ molecule has a steric number of 4 , which yields a predicted bond angle of $109.5^{\circ}$. The four elements form a tetrahedron, with the $\mathrm{O}$ atom at the centre and the two $\mathrm{H}$ atoms and two lone pairs at the vertices. The molecule has a tetrahedral electron pair geometry. The measured value is approximately $104.5^{\circ}$ because the lone pairs repel more strongly than the pairs used in covalent bond formation. The molecular geometry of $\mathrm{H}_{2} \mathrm{O}$ is bent, as seen in the following diagram: 


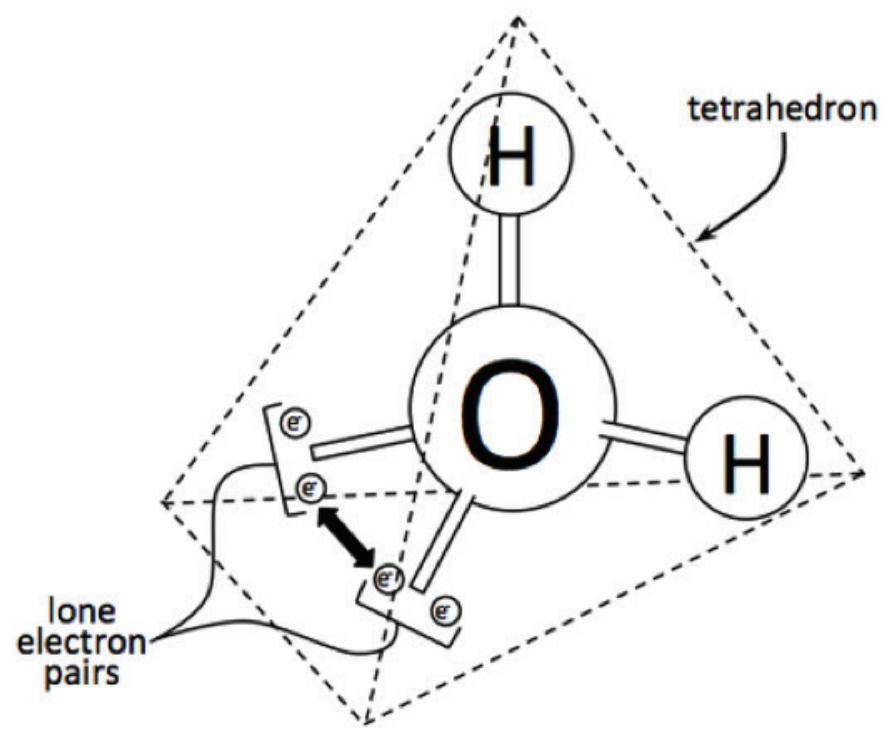

The bent structure of a water molecule.

Figure 1

We can now deduce that the water molecule itself is polar, because of the non-linear arrangement of the two polar O-H bonds. The dipole moment of $\mathrm{H}_{2} \mathrm{O}$ is a measure of how much the two bond dipoles point in the same direction, and is responsible for properties such as hydrogen bonding and the alignment of $\mathrm{H}_{2} \mathrm{O}$ molecules in an electric field. The resultant dipole moment $\mu_{\text {res }}$ of the $\mathrm{H}_{2} \mathrm{O}$ molecule is the vector product of the two equal O-H bond dipoles $\mu_{\mathrm{OH}}$ :

$$
\mu_{r e s}=2 \mu_{\mathrm{OH}} \cos \left(\frac{\theta}{2}\right)
$$

Where $\theta$ is the angle between the two $\mathrm{O}-\mathrm{H}$ bonds. Here $\mu_{\text {res }}$ is the sum of the components of the two $\mathrm{O}-\mathrm{H}$ bond dipoles that point in the same direction, and hence do not cancel out, due to the non-linearity of the $\mathrm{H}_{2} \mathrm{O}$ molecule. If $\theta$ were $180^{\circ}$, the dipole moment would be zero, since $\cos \left(90^{\circ}\right)=\mathrm{O}$. Like $\mathrm{H}_{2} \mathrm{O}, \mathrm{CO}_{2}$ contains two polar bonds, but unlike $\mathrm{H}_{2} \mathrm{O}$, the central $\mathrm{C}$ atom has no lone pairs, resulting in a linear molecule in which two equal and oppositely directed bond dipoles cancel out. For present purposes, the point of interest is that the bond angle plays a crucial role in determining $\mu_{\text {res }}$. As we vary the bond angle $\theta$ between 
$0^{\circ}$ and $180^{\circ}$, the factor by which we multiply the bond dipole vectors to get the resultant varies between 1 and $0 .{ }^{28}$

Molecular geometry is a qualitatively realized property, and the tripartite bent geometry of $\mathrm{H}_{2} \mathrm{O}$ is realized by the basic physical structure of the molecule. The property that features in the above explanation is the qualitatively realized property, not its basic physical realizer. While the $\mathrm{O}-\mathrm{H}$ bond lengths play a role in determining the $\mathrm{O}-\mathrm{H}$ bond dipoles, the specific distance relations between the atoms play no further role in the explanation of the dipole moment of $\mathrm{H}_{2} \mathrm{O}$ except insofar as they represent one way to have a tripartite bent geometry with a bend of $104 \cdot 5^{\circ}$. According to the equation just given for the resultant dipole moment, its value depends only on the $\mathrm{O}-\mathrm{H}$ bond dipoles and the angle between the bonds. Let $\mathrm{G}$ be the property of being composed of three proper parts $x, y$ and $z$, arranged such that $z$ is equidistant from $x$ and $y$, and straight lines drawn between $x$ and $z$ and $y$ and $z$ subtend an angle of 104.5. Highly diverse physical structures can have $\mathrm{G}$-not only $\mathrm{H}_{2} \mathrm{O}$ molecules but also molecular models, for instance-in many different ways and for many different reasons. To instantiate $G$ is to be an $X$ that meets a mathematical specification in virtue of the properties and relations of its proper parts. While there are (of course) causal explanations of how such an $X^{\prime}$ s proper parts get to be so structured as to instantiate $G$, andat least in the case of $\mathrm{H}_{2} \mathrm{O}$ - why their realization of $\mathrm{G}$ is diachronically stable, $\mathrm{G}$ is qualitatively, not functionally, realized.

Now the reader may well suspect at this point that it's the basic physical structure of the molecule, rather than its qualitatively realized geometry, that's really doing the causal work in relation to the dipole moment, with geometry no more than a useful explanatory proxy. I take up the challenge of arguing against this intuitive position in the next section. For now, I merely wish to highlight the role that $\mathrm{G}$ plays in explaining the dipole moment of $\mathrm{H}_{2} \mathrm{O}$, and the causal powers it bestows through this role, leaving open whether it inherits these powers from its realizers. In general, a body's shape determines the range of possible ways in which a quantitative basic physical property such as electric charge can be distributed over it. One way for charge to be distributed over bearers of $\mathrm{G}$ is such that it is concentrated towards the central component $z$, relative to $x$ and $y$, which is bound to yield a resultant dipole moment, as the $x-z$ and $y-z$ dipoles won't fully cancel out. The various forces at work in the $\mathrm{H}_{2} \mathrm{O}$ molecule result in a charge distribution that gives rise to two $\mathrm{O}-\mathrm{H}$ bond dipoles. Given that $\mathrm{H}_{2} \mathrm{O}$ has a bent molecular geometry, this results in a molecule with a non-zero net dipole moment, as the two vectors share components in the same direction. Holding everything else fixed, we can imagine varying the bond angle $\theta$ between $o^{\circ}$ and

28. The $\mathrm{O}-\mathrm{H}$ bond dipoles are of magnitude $1.5 \mathrm{D}$, where $1 \mathrm{D}=3.34 \times 10^{-30} \mathrm{Cm}$. Using these values in the above equation, the magnitude of the resultant dipole moment of $\mathrm{H}_{2} \mathrm{O}$ is $1.84 \mathrm{D}$. In practice, the bond dipoles are calculated from a measured value for the dipole moment of $\mathrm{H}_{2} \mathrm{O}$. 
$180^{\circ}$, resulting in a net dipole moment $\mu_{\text {res }}$ that varies between $2 \mu_{O H}$ and o, with the cosine of $\theta / 2$.

$\mathrm{H}_{2} \mathrm{O}$ molecules have a range of powers in virtue of their dipole moments, such as the power to align in an electric field. Microwave ovens rely on this power to heat food, subjecting it to an oscillating electric field that accelerates its constituent $\mathrm{H}_{2} \mathrm{O}$ molecules as they flip their orientation to match the orientation of the field, thereby increasing the temperature of the food. Because $G$ plays a role in determining the dipole moment of $\mathrm{H}_{2} \mathrm{O}$, it thereby plays a role in determining that $\mathrm{H}_{2} \mathrm{O}$ molecules have this power. Because many other properties are involved, it's natural to say that $\mathrm{G}$ bestows conditional powers, in Shoemaker's sense, upon $\mathrm{H}_{2} \mathrm{O}$ (2001: 25-26). For $X$ to have a power simpliciter is for it to be disposed to behave in a certain way, when appropriately related to certain stimuli. For $X$ to have a conditional power is for it to be such that if it had certain other properties, it would have the relevant power simpliciter, where the other properties in question are not independently sufficient for this. Necessarily, every $X$ such that $G(X)$, has (inter alia) the power to align in an electric field, conditionally on (I) X's being such that its proper parts $x, y$ and $z$ are bonded together so that $\mathrm{G}(X)$ is stable under an electric field, and (2) $z$ being negatively charged relative to $x$ and $y$. We have already seen above how the $\mathrm{H}_{2} \mathrm{O}$ molecule meets these conditions, but there are many other ways. A molecular model with $\mathrm{G}$ might meet them by being composed of three charged conducting spheres connected by conducting metal rods, suspended so as to allow sufficient degrees of rotational freedom to align (or else in free fall), and being such that the $z$ sphere is more electronegative than both $x$ and $y$. Let us label this conditional power ' $\psi$ '.

In addition to the powers simpliciter that it undoubtedly bestows, electric charge also bestows conditional powers: the power to align in an electric field conditionally on being an $X$ with $G$, being bonded so that $X$ 's geometry is stable under an electric field, and being such that $z$ is negatively charged relative to $x$ and $y$, for instance. The difference between this conditional power and $\psi$ highlights the different roles that molecular geometry and charge play in determining how the $\mathrm{H}_{2} \mathrm{O}$ molecule is disposed, by dint of their different roles in determining its dipole moment. As Shoemaker notes (2001: 25), conditional powers enable us to isolate the causal contributions of individual properties to a power simpliciter when-as is commonplace - that power is jointly bestowed by several properties. To bestow a conditional power upon $X$ is to be one of several properties that jointly determine how $X$ is disposed to behave under certain circumstances. I have argued in this section that $\mathrm{G}$ partially determines the dipole moment of $\mathrm{H}_{2} \mathrm{O}$, and thereby bestows conditional power $\psi$ upon $\mathrm{H}_{2} \mathrm{O}$ molecules, which is to say that $\mathrm{G}$ plays a specific role in determining that $\mathrm{H}_{2} \mathrm{O}$ molecules are disposed to align in an electric field. 


\section{The Causal Fundamentality of Molecular Geometry}

In this section $\mathrm{I}$ argue that $\mathrm{H}_{2} \mathrm{O}$ molecules do not have $\psi$ in virtue of their basic physical properties, and that $\mathrm{G}$ is therefore a strongly emergent property according to (Strong'), for it bestows a causal power that its realizers do not. To clarify my position, I'll first contrast it with Hilary Putnam's views on the causal role of shape, and his associated alternative proposal concerning the autonomy of psychology. Putnam compares functionally realized psychological properties to geometric properties, and argues by analogy that despite the fact that they don't bestow novel powers, such properties nonetheless have a kind of explanatory novelty that suffices for the autonomy of psychology (1975: 130-132). Putnam asks us to consider a board with a round hole, and a square peg that doesn't fit through it. Putnam grants that this fact is deducible from basic physics, but argues that the deduction doesn't count as a good explanation. The geometric explanation is fully general, applying to objects of the same shape regardless of how their shapes are realized, whereas the basic physical deduction works only for things that are physically like the peg and board-things whose shapes are realized in just the same way. Here, as Putnam sees it, we have a case of the explanatory novelty of shape despite the fact that all the causal powers of the peg and board are bestowed by their basic physical properties.

A plausible interpretation of Putnam's peg case is that the geometric explanation is a program explanation. On any given occasion, a token failure of the square peg to fit through the round hole can be fully causally explained in terms of the basic physical properties of the peg and board. The shapes of the peg and board, however, make certain that whenever we try to fit the square peg through the round hole, some basic physical process will be operative such that some parts of the peg and board collide resulting in a failure to fit. What we are attempting to do is impossible, given the shapes of the peg and board, so there's bound to be some token physical process that prevents us from doing it on any given occasion. The program explanation thus applies across all possible realizations of the same shapes, and thereby conveys modal information that particular process explanations lack (Jackson \& Pettit 1990). ${ }^{29}$

On certain modal theories of causation, this kind of modal novelty entails causal novelty. Christian List and Peter Menzies (2010) argue from modal novelty to causal novelty on this basis, concluding that special science properties are strongly emergent, at least according to Wilson's (Strong). ${ }^{30}$ Given a differencemaking account of causation, a realized property-instance can cause some effect

29. See Baron and Colyvan (2016) for full discussion of program explanation as applied to Putnam's peg and board case, and for intriguing connections between it (and other, similar cases of non-causal mathematical explanation) and Lewis's solution to the grandfather paradox.

30. Note that List and Menzies do not characterize their position as a form of emergence. 
its realizer does not. ${ }^{31}$ Roughly, according to such accounts, F causes G iff (i) F occurs $\square \rightarrow$ G occurs, and (ii) $\neg$ (F occurs) $\square \rightarrow \neg$ (G occurs). Now take a realized mental property instance $\mathrm{M}$, its physical realizer $\mathrm{P}$, and a behavioural property instance $B$ caused by $M$. If we suppose that the causal relationship between $M$ and $\mathrm{B}$ is realizer-invariant, in that $\mathrm{B}$ occurs at the nearest $\mathrm{M}$-worlds that are not $\mathrm{P}$-worlds (i.e., the nearest worlds where $\mathrm{M}$ is differently realized), then $\mathrm{P}$ isn't a difference-making cause of $\mathrm{B}$. The reason is that not-P worlds where $\mathrm{M}$ occurs are closer to actuality than not-P worlds where $\mathrm{M}$ doesn't occur, and at such worlds, B occurs just the same, so it's false that had P not occurred, B would not have occurred. List and Menzies assume that difference-making causes manifest the power to cause their effects and conclude that $\mathrm{M}$ has a power-viz. the power to cause $\mathrm{B}$ - that $\mathrm{P}$ lacks, which renders $\mathrm{M}$ emergent according to (Strong).

Now whether $\mathrm{M}$ is strongly emergent according to (Strong') depends on whether $\mathrm{M}$ has its modal properties in virtue of its realizer P. Since P by hypothesis lacks these modal properties, $M$ can't inherit them directly from $\mathrm{P}$. We might say that $M$ is causally individuated, and hence gets its modal profile from its causal powers, which are in turn inherited from $\mathrm{P}$, but that seems to get things backwards: on the difference-making theory, causal powers are explained in terms of the modal profiles of property-instances, not vice-versa. It's not at all clear to me where token events and physical objects get their de re modal properties, or indeed whether they have de re modal properties at all, but such matters are beyond the scope of the present work. Suffice it to say that if M doesn't have its modal profile in virtue of $\mathrm{P}$, then given difference making causation, and once again assuming that difference-making causes manifest the power to cause their effects, it follows that $\mathrm{M}$ is strongly emergent according to (Strong') as well.

Problematically, because $\mathrm{P}$ is a sufficient cause of $\mathrm{B}^{\prime} \mathrm{s}$ realizer $\mathrm{P}^{\prime}$, there is surely some causal-explanatory relationship between $\mathrm{P}$ and $\mathrm{B}$, even if it's not (difference-making) causation. ${ }^{32}$ If we think of B as a modally fragile event essentially realized by $\mathrm{P}^{\prime}$, then $\mathrm{B}$ has a complete non-psychological cause P. It's only if we think of $\mathrm{B}$ as a modally robust event that spans a neighbourhood of close possible worlds that we need a similarly robust event, $M$, as its cause. In effect, $\mathrm{P}$ causes the particular realization $\mathrm{P}^{\prime}$ of $\mathrm{B}$ that happens at our world, with $\mathrm{M}$ taking up the modal slack of causing occurrences of $B$ at nearby worlds where $P$ is absent. Those sceptical of the ascription of de re modal properties to token events may suspect that the problem with the basic physical explanation of $\mathrm{B}$ in terms of $\mathrm{P}$ is not that $\mathrm{P}$ fails to cause $\mathrm{B}$, but that the causal explanation of $\mathrm{B}$ in terms of $\mathrm{P}$ fails to apply to relevantly similar actual cases, in which other individuals have an M-instance that causes a B-instance, but fail to have either P or P'. Opponents

31. This is the central message of Yablo (1992).

32. Cf. Yablo (1992: 274), where he distinguishes causation proper, construed in differencemaking terms, from causal sufficiency, which holds between P and B. 
of a layered model supported by difference-making causation can now argue that it mistakes facts about our explanatory practices for facts about the causal structure of the world. That the basic physical causes of certain phenomena seem too specific shows only that when it comes to explaining those phenomena, we often value the explanatory generality provided by program explanations.

I'm happy to grant that geometric explanations such as that found in Putnam's peg case are program explanations. Rather than appeal to modal considerations to argue that molecular geometry is causally fundamental, I shall instead argue that it plays a unique and ineliminable role in the process explanation of any token alignment of $\mathrm{H}_{2} \mathrm{O}$ molecules in an electric field. Molecular geometry does not merely program for whatever basic physical properties genuinely cause such alignments on some occasion, nor does its causal-explanatory value consist solely in generality. I shall argue in the remainder of this section that the dipole moment of $\mathrm{H}_{2} \mathrm{O}$ cannot be explained without appealing to the geometry $\mathrm{G}$ of the molecule, which is to say that it has no purely basic physical explanation. There's no question of $\mathrm{G}$ being a mere program explainer of a token alignment of $\mathrm{H}_{2} \mathrm{O}$ molecules in an electric field, for it plays a unique role in determining that they have the power simpliciter to so align.

The structure of the argument is as follows: (i) $G$ plays a role, alongside basic physical properties, in determining the dipole moment of the $\mathrm{H}_{2} \mathrm{O}$ molecule; (ii) $\mathrm{H}_{2} \mathrm{O}$ molecules have a range of powers in virtue of their dipole moments, such as the power to align in an electric field; (iii) because $G$ plays a partial role in determining the dipole moment of $\mathrm{H}_{2} \mathrm{O}$, $\mathrm{G}$ bestows corresponding conditional powers such as $\psi$ upon it; (iv) if $\mathrm{G}$ inherits $\psi$ from its basic physical realizers, then we can explain the dipole moment of $\mathrm{H}_{2} \mathrm{O}$ without appealing to $\mathrm{G}$; however, (v) we cannot explain the dipole moment of $\mathrm{H}_{2} \mathrm{O}$ without appealing to $\mathrm{G}$. Conclusion: $\mathrm{G}$ does not inherit $\psi$ from its basic physical realizers, and is strongly emergent according to (Strong'). I argued for premises (i)-(iii) in Section 3. Premise (v) bears the central argumentative burden, but let me first offer some remarks in support of premise (iv). It's important to bear in mind that $\mathrm{G}$ bestows $\psi$ upon $\mathrm{H}_{2} \mathrm{O}$ by dint of its role in determining the dipole moment of the molecule. To say that $G$ inherits $\psi$ from its basic physical realizers is therefore to say that these latter must really do what $\mathrm{G}$ does in determining the dipole moment, which, as we've seen, is to determine the extent to which the $\mathrm{O}-\mathrm{H}$ bond dipoles point in the same direction. Now if G's basic physical realizers occupy G's role in determining the dipole moment, it follows that we should be able to explain the dipole moment by appealing to those properties in place of $G$. Hence, if $G$ inherits $\psi$ from its realizers, we can explain the dipole moment without appealing to G. Conversely, if we can't explain the dipole moment without appealing to $G$, then it and it alone bestows $\psi$.

Let's turn now to premise (v). Because its dipole moment is a property of the 
$\mathrm{H}_{2} \mathrm{O}$ molecule, it's appropriate to cast the question of whether it has a purely basic physical explanation in terms of whether it can be deduced from basic physical properties and laws, without appealing to the geometry of the molecule. If it can be so deduced, then the dipole moment has a wholly basic physical explanation, and G's conditional powers are inherited. I needn't endorse a deductivenomological account of explanation in general; the point is rather that deducibility is the appropriate explanatory model in the present case. I shall argue that while the dipole moment of $\mathrm{H}_{2} \mathrm{O}$ can be deduced from basic physics, the deduction cannot proceed without appealing to $G$. Because $G$ is qualitatively realized, $G$ itself can be deduced from the basic physical properties of $\mathrm{H}_{2} \mathrm{O}$. From this, however, it doesn't follow that the dipole moment of $\mathrm{H}_{2} \mathrm{O}$ has a complete basic physical explanation. What follows is that a crucial component of the explanation $-\mathrm{G}-$ has a complete basic physical explanation. Having deduced $\mathrm{G}$ from the basic physical properties of the $\mathrm{H}_{2} \mathrm{O}$ molecule, we can then only deduce the dipole moment by appealing to basic physics and $\mathrm{G}$ together.

Proponents of the causal inheritance principle will think that $G$ inherits its conditional powers from the specific spatial structure formed by the three constituent atoms of $\mathrm{H}_{2} \mathrm{O}$-from the basic physical properties and relations that realize $\mathrm{G}$ in the $\mathrm{H}_{2} \mathrm{O}$ molecule. Let the $\mathrm{O}-\mathrm{H}$ bond length be $\mathrm{B}$; it's easy to show that the distance $D$ between the two $\mathrm{H}$ atoms is given by:

$$
D=2 B \sin \left(\frac{\theta}{2}\right)
$$

Where $\theta$ is the bond angle, $104.5^{\circ}$. It follows that $D=1.58 \mathrm{~B}$. We can now specify how $\mathrm{G}$ is realized in $\mathrm{H}_{2} \mathrm{O}$ : $\mathrm{G}$ is realized by two $\mathrm{H}$ atoms each a distance $\mathrm{B}$ from a single $\mathrm{O}$ atom, and $1.58 \mathrm{~B}$ from each other. Being so constituted is one of countless ways for a tripartite structure to have a bent geometry with a bend of $104.5^{\circ}$. If, in the explanation of the dipole moment of $\mathrm{H}_{2} \mathrm{O}, \mathrm{G}$ is merely a proxy for these specific distance relations, we should be able to deduce the dipole moment by replacing $\mathrm{G}$ with the relations in question. Consider the set of basic physical properties of the $\mathrm{H}_{2} \mathrm{O}$ molecule other than the distance relations between the atomsthe charge of the electrons, the electronegativity of the atoms, and so forth. Our question is: can we deduce the dipole moment of $\mathrm{H}_{2} \mathrm{O}$ by adding only the specific distance relations to this set of properties? The reader may find it more natural to think in terms of the structural property formed by combining all the basic physical properties and relations of the molecule, but this adds nothing of explanatory significance. If we can't explain the dipole moment of $\mathrm{H}_{2} \mathrm{O}$ by appealing to its basic physical properties and relations, then expressing those properties and relations by means of a single complex predicate won't help. How should the explanation proceed? The obvious option is to use the distance relations to draw a diagram of the molecule: 


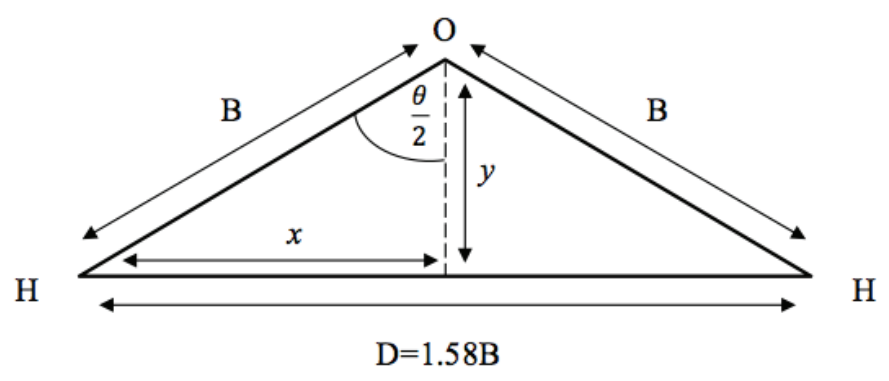

Figure 2

Drawing the molecule to scale allows us to see that it's non-linear, hence that the resultant dipole can't be zero; it also allows us to measure the bond angle, and calculate the dipole moment based on the equation given in Section 3. However, this is simply to use the basic physical relations to determine the molecule's geometry, and then appeal to its geometry to deduce the dipole moment. That, it goes without saying, is not to deduce the dipole moment without appealing to G. Suppose it's now objected that we can see that the molecule is polar without drawing it, simply by reflection on its basic physical properties and relations. Given that the O-H bonds are polar, the molecule will be polar if it is also nonlinear. Now it must be non-linear, for if it were linear, then $D=2 B$. Given that $D<2 B$, the molecule must be bent, hence must have a non-zero resultant dipole. Once more, however, we have simply appealed to the basic physical properties of the molecule to determine that the bond angle $\theta<180^{\circ}$. While this isn't the same property as $G$, it's still a multiply realizable geometric property; and what's more, it doesn't enable us the deduce magnitude of the dipole. If we want to do that, we need to know the degree of non-linearity, for which we need to know the bond angle.

Perhaps we can do better. Each $\mathrm{O}-\mathrm{H}$ bond dipole, you will recall from Section 3 , is given by $\mu_{\mathrm{OH}}=\delta \mathrm{B}$, and directed from the relatively positive $\mathrm{H}$ atoms to the relatively negative $\mathrm{O}$ atom. We can resolve each of the two $\mathrm{O}-\mathrm{H}$ bond dipoles into component vectors at right-angles. The left-hand dipole is shown below, resolved into $x$ and $y$ components:

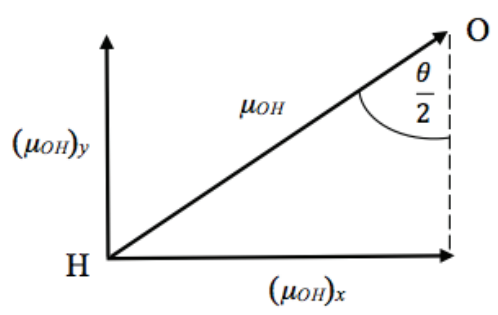

Figure 3 
The component $\left(\mu_{\mathrm{OH}}\right)_{x}$ is cancelled out by an equal and opposite component of the right-hand dipole, with $\left(\mu_{\mathrm{OH}}\right)_{y}$ the component that isn't cancelled, and $2\left(\mu_{\mathrm{OH}}\right)_{y}$ the magnitude of the resultant $\mu_{\text {res }}$. The relative magnitudes of the three vectors above are represented by the relative lengths of the corresponding sides of the triangle. Crucially, the vectors form a similar triangle to that formed by each half of the molecule, so the ratio $y: B$ in the molecule is equal to the ratio $\left(\mu_{\mathrm{OH}}\right)_{y}:\left(\mu_{\mathrm{OH}}\right)$ of the magnitudes of the vectors:

$$
\frac{y}{B}=\frac{\left(\mu_{\mathrm{OH}}\right)_{y}}{\mu_{\mathrm{OH}}}
$$

Rearranging, we can see that the magnitude of $\left(\mu_{\mathrm{OH}}\right)_{y}$ is equal to the fraction $y / \mathrm{B}$ of $\mu_{\mathrm{OH}}$ :

$$
\left(\mu_{\mathrm{OH}}\right)_{y}=\left(\frac{y}{B}\right) \mu_{\mathrm{OH}}
$$

We can now appeal to the basic physical properties we know to calculate the value of $y / \mathrm{B}$. We divide the molecule into two right-angle triangles, as in the diagram, so that $x=(\mathrm{D} / 2)=0.79 \mathrm{~B}$. We can calculate the value of $y$ in terms of $\mathrm{B}$, using Pythagoras' theorem: $\mathrm{B}^{2}=y^{2}+(0.79 \mathrm{~B})^{2}$, giving a value of $y=0.61 \mathrm{~B}$. Hence $y / \mathrm{B}=0.61$, and $\left(\mu_{\mathrm{OH}}\right)_{y}=0.61 \mu_{\mathrm{OH}}$. It follows that $\mu_{\text {res }}=1.22 \mu_{\mathrm{OH}}$. We know that $\mu_{\mathrm{OH}}=1.5 \mathrm{D}, 33$ hence $\mu_{r e s}=1.84 \mathrm{D}$. Alternatively, we can substitute $\mu_{\mathrm{OH}}=\delta \mathrm{B}$ in the previous equation, in which case $(y / B) \mu_{O H}=\delta y$. We know the value of the charge difference $\delta$, and we can calculate the value of $y$ as above, given that we know the value of $\mathrm{B}$.

Haven't we now deduced the dipole moment of $\mathrm{H}_{2} \mathrm{O}$ by appealing to $\mathrm{G}^{\prime}$ 's realizers, the spatial relations between the atoms, in place of G? First, even if we grant that the above deduction makes no appeal to G, it's clearly not a wholly non-geometric explanation, as it assumes we can we divide the molecule into two right-angle triangles, which in turn depends on mirror symmetry in the plane of the molecule. Second, the deduction does appeal to G: we didn't just appeal to basic distance relations, but to ratios of such relations, and the ratios in question are geometric. We first assumed that the two triangles were similar, which is to assume that their internal angles are the same. It's because the angle between $y$ and $\mathrm{B}$ is equal to the angle between $\left(\mu_{\mathrm{OH}}\right)_{y}$ and $\mu_{\mathrm{OH}}$ that the ratios of $y: \mathrm{B}$ and $\left(\mu_{\mathrm{OH}}\right)_{y}: \mu_{\mathrm{OH}}$ are the same-as will no doubt be familiar, they are both equal to $\cos (\theta / 2)$. Recall our equation of Section 3 for $\mu_{\text {res }}$ :

33. See Footnote 28. 


$$
\mu_{r e s}=2 \mu_{\mathrm{OH}} \cos \left(\frac{\theta}{2}\right)
$$

In this equation, $\cos (\theta / 2)$ gives the extent to which the two $\mathrm{O}-\mathrm{H}$ bond dipoles point in the same direction. All that our putatively non-geometric derivation achieves is to show that there's another way of calculating that extent to which these two dipoles point in the same direction. We can substitute $\cos (\theta / 2)$ with $y / B$, which gives us the following alternative equation:

$$
\mu_{\text {res }}=2\left(\frac{y}{B}\right) \mu_{\mathrm{OH}}
$$

But the ratio $y / B$ gives the extent to which the two dipoles point in the same direction precisely because it encodes the angle between them. As $y / \mathrm{B}$ tends to zero, so the molecule tends towards linearity and the resultant dipole moment $\mu_{\text {res }}$ of the molecule tends to zero; the closer its value is to unity, the greater the resultant. This isn't to deduce the resultant dipole moment without appealing to $G$, but to appeal to $G$ under an alternative mode of presentation.

If we attempt to deduce the dipole moment of $\mathrm{H}_{2} \mathrm{O}$ from basic physics without appealing to molecular geometry, we draw a blank, for no sooner have we started the deduction than we find ourselves deducing that $\mathrm{H}_{2} \mathrm{O}$ has $\mathrm{G}$ as an essential intermediary step. I conclude that molecular geometry plays a unique role in determining the dipole moment of $\mathrm{H}_{2} \mathrm{O}$, and in virtue of this bestows a conditional power $\psi$ that it doesn't inherit from its basic physical realizers. Assuming that (Strong') is the right way to characterize strong emergence, and that conditional powers are within its scope, then given that $G$ is a dependent property, it is also strongly emergent. Let me remind the reader of some claims I made in Section 1: (a) G does not generate new forces, nor is it governed by sui generis causal laws; (b) G's effects are not an additive sum of the effects of its basic physical realizers; (c) G's role in determining the dispositions of water molecules is a case of downward causation; (d) G is deducible from basic physics. We are now in a position to understand why these claims are true, and how they are consistent.

(a) In determining the range of possible ways charge can be distributed over its bearers, G clearly doesn't exert a force on the charge-bearing electrons. It's the various forces acting on the electrons combined with the shape of a given charge bearer that determine its charge distribution. While the electrons are attracted to the $\mathrm{H}$ and $\mathrm{O}$ atoms that compose the molecule by Coulomb forces, the shape of the resulting charge cloud depends not only on the magnitude of those forces, but also on the shape of the molecule. In particular, it's the degree of non-linearity, specified by $\mathrm{G}$, that determines the extent to which the $\mathrm{O}-\mathrm{H}$ bond dipoles don't cancel each other out. Molecular geometry exerts no forces, but not all the causal pow- 
ers that properties bestow are powers to exert forces, because there's far more to causation than just doing physical work. We don't need sui generis laws to explain what $G$ does precisely because its causal powers are not powers to exert forces; $G$ partially determines the dipole moment of $\mathrm{H}_{2} \mathrm{O}$ solely by being the property it is. Once we have its mathematical specification to hand, nothing further is needed to explain why it bestows the conditional powers that it does.

(b) The effects of functional properties are additive sums of the effects of their realizers. Let's say that rigidity bestows the power to maintain shape under a force. Suppose a force is applied to a body X on some occasion, and the bonds between $X^{\prime}$ s basic physical parts absorb the supplied energy without breaking. This preserves the spatial relations between $X^{\prime}$ s proper parts, ensuring that its shape stays constant under the force. Any token effect of $X^{\prime}$ 's rigidity is identical to the combined effects of its basic physical realizers, and that's as it should be, because rigidity is functionally realized. Functional properties inherit their powers from their realizers, so it's no surprise that what they cause reduces to what their realizers cause; that's what functional realization is. By contrast, the effect of molecular geometry in a token alignment of an $\mathrm{H}_{2} \mathrm{O}$ molecule in an electric field is not an additive sum of the effects of its realizers, although it's impossible to isolate a token effect of which $\mathrm{G}$ alone is the cause. Remember that $\mathrm{G}$ bestows a specific, novel conditional power to align in an electric field, which is to say that it's one of several properties that jointly bestow the corresponding power simpliciter. A token alignment of an $\mathrm{H}_{2} \mathrm{O}$ molecule in an electric field is the combined effect of all these properties acting together. It's difficult to see how to divide up such an effect between the contributing properties, but I think it clear that because $\mathrm{G}^{\prime}$ s role in determining the dipole moment of $\mathrm{H}_{2} \mathrm{O}$ is not occupied by its basic physical realizers, its contribution to a token alignment is not an additive sum of theirs.

(c) To bestow a conditional power upon $X$ is to partially determine how $X$ is disposed to behave. Because $\mathrm{G}$ plays a novel role in determining how $\mathrm{H}_{2} \mathrm{O}$ molecules are disposed to behave, and $\mathrm{H}_{2} \mathrm{O}$ molecules are composed of basic physical particulars, G's effects are a case downward causation. My position therefore violates at least one causal closure principle. According to a standard formulation of the closure principle, all physical effects are fully caused (or have their chances determined) by purely physical prior histories (Papineau 2002: 17-18).34 If we take 'physical' to mean basic physical, then the physical is not causally closed, because some properties that play a novel role in determining what goes on there aren't basic physical properties. However, physicalists typically don't interpret 'physical' in this way. Rather, they think that 'physical' means broadly

34. The precise formulation is unimportant for present purposes. For more on why closure principles must stipulate that physical effects have full or complete physical causes, see Yates (2009). 
physical, and refers to anything that is either basic physical, or stands in some appropriate relation to basic physical entities. 35 Provided qualitative realization is an appropriate relation, the causal closure of the broadly physical is safe. I think it clear that broad physicality is closed under qualitative realization, but even if it weren't, the causal fundamentality of molecular geometry would refute the causal closure of the broadly physical, and not vice-versa.

(d) I grant that we can deduce that $\mathrm{H}_{2} \mathrm{O}$ has $\mathrm{G}$ from the basic physical properties and relations of its constituent atoms. Readers familiar with the longstanding tradition of contrasting emergence with deducibility will no doubt find it surprising that a deducible property could be causally fundamental, but on reflection, it should be no more surprising than the central thesis of this paperthat strong emergence is consistent with physical realization. The mere fact that a qualitatively realized property is deducible from basic physics doesn't suffice to show that its causal powers are inherited. To show that G inherits its conditional powers from its basic physical realizers, we would need to deduce the dipole moment of $\mathrm{H}_{2} \mathrm{O}$ from its basic physical properties without appealing to $G$-and this, I have argued, cannot be done. We can only deduce the dipole moment of $\mathrm{H}_{2} \mathrm{O}$ by appealing both to basic physical properties and laws and its geometry. Given that ' $x$ is deducible from $y$ ' expresses a transitive relation, it follows that the dipole moment of $\mathrm{H}_{2} \mathrm{O}$ is likewise deducible from basic physics. ${ }^{36}$ In the deduction, however, $\mathrm{G}$ is an essential intermediate step, which is just what we would expect if $\mathrm{G}$ were both causally fundamental and deducible. These deducibility relations exactly reflect the metaphysical structure for which I have argued: $\mathrm{H}_{2} \mathrm{O}$ has $\mathrm{G}$ in virtue of its basic physical properties, but it has its dipole moment in virtue of its basic physical properties and $\mathrm{G}$, with $\mathrm{G}$ playing a crucial role in determining the resultant of the two $\mathrm{O}-\mathrm{H}$ bond dipoles.

At this point, however, a problem arises. I appeal to 'in virtue of' relations twice here: once in the realization relation between the basic physical properties of $\mathrm{H}_{2} \mathrm{O}$ and $\mathrm{G}$, and again between $\mathrm{G}$ and conditional powers such as $\psi$, which reflect $\mathrm{G}^{\prime}$ s putatively unique role in determining how $\mathrm{H}_{2} \mathrm{O}$ molecules are disposed. But if 'in virtue of' is transitive, then $\mathrm{H}_{2} \mathrm{O}$ has $\psi$ in virtue of its basic physical properties, precluding G's causal fundamentality.

\section{The Grounding Objection}

Following Kit Fine (2002: Section 1), let us suppose that metaphysical grounding is an explanatory relation holding between facts: the fact that A grounds the fact

35. See for instance Crook and Gillett (2001).

36. I thank an anonymous referee for pressing me on this point. 
that $B$ iff the fact that $B$ obtains in virtue of the fact that $A$, and it is metaphysically necessary that if $\mathrm{A}$ then $\mathrm{B} .37$ I hold that the $\mathrm{H}_{2} \mathrm{O}$ molecule's geometry is qualitatively realized by its basic physical properties, and qualitative realization seems a clear case of metaphysical grounding. It's in virtue of its basic physical properties and relations that $\mathrm{H}_{2} \mathrm{O}$ meets the specification that defines $\mathrm{G}$, and it's metaphysically necessary that anything having those properties meets that specification. I argued in Sections 3-4 that it's solely in virtue of meeting the qualitative specification that defines $\mathrm{G}$ that $\mathrm{H}_{2} \mathrm{O}$ has $\psi$. However, because $\psi$ is a conditional power, it's metaphysically necessary that G-bearers have $\psi$. It follows that the fact that $\mathrm{H}_{2} \mathrm{O}$ has $\psi$ is grounded in the fact that it has $\mathrm{G}$. If grounding is transitive, then the fact that $\mathrm{H}_{2} \mathrm{O}$ has $\psi$ is grounded in its basic physical properties, in which case $\mathrm{H}_{2} \mathrm{O}$ has $\psi$ in virtue of its basic physical properties, and $\mathrm{G}$ is not strongly emergent.

My response to the grounding objection doesn't depend on denying the transitivity of grounding. Instead, I shall argue that the basic physical grounding of $\psi$ is consistent with G's being strongly emergent. The basic physical properties that realize $\mathrm{H}_{2} \mathrm{O}^{\prime}$ s molecular geometry are those in virtue of which it meets a mathematical specification; and in virtue of meeting that specification, $\mathrm{H}_{2} \mathrm{O}$ has $\psi$. These are two quite distinct grounding relations, but this crucial fact is obscured by focusing on their shared abstract properties. Following Wilson (2014), I distinguish this abstract grounding relation from specific grounding relations such as realization by labelling the former 'Grounding' (with a capital ' $\mathrm{g}$ '), and shall argue that Grounding is too coarse-grained to capture the metaphysical structure of my emergentist proposal, which requires two distinct littleg grounding relations. Basic physics mediately grounds $\psi$ via one grounding relation - qualitative realization - between basic physics and molecular geometry, and a distinct grounding relation - causal power bestowal-between $\mathrm{G}$ and $\psi$. That these relations are both instances of Grounding does not entail that $\psi$ is really bestowed by the $\mathrm{H}_{2} \mathrm{O}$ molecule's basic physical properties. Let me explain.

I accept that there's a sense in which $\mathrm{H}_{2} \mathrm{O}$ has $\psi$ in virtue of its basic physical properties. Must I not therefore retract the central claim of this paper, viz. that $\mathrm{H}_{2} \mathrm{O}$ has $\psi$ solely in virtue of $\mathrm{G}$ ? No-but I do need to disambiguate the various 'in virtue of' claims involved. Let us write the qualitative realization relation between $\mathrm{H}_{2} \mathrm{O}^{\prime}$ s basic physical properties and $\mathrm{G}$ as follows:

1) $\mathrm{H}_{2} \mathrm{O}$ has $\mathrm{G}$ in-virtue-of ${ }_{Q R}$ its basic physical properties

37. Here 'in virtue of' is a sui generis relation appropriate to claims of metaphysical explanation. The relation is hyperintensional: the fact that Socrates exists grounds the fact that \{Socrates\} exists, but not vice versa, despite the fact that necessarily, Socrates exists iff \{Socrates\} exists. Grounding is therefore not amenable to reductive modal analysis. 
Now let us write the causal power bestowal relation between $\mathrm{H}_{2} \mathrm{O}^{\prime}$ s geometry and $\psi$ as follows:

\section{2) $\mathrm{H}_{2} \mathrm{O}$ has $\psi$ in-virtue-of $\mathrm{CP}_{C P}$ its having $\mathrm{G}$}

The 'in-virtue-of $\mathrm{f}_{C P}$ ' relation is whatever relation holds between a property and its bearers when that property plays a role in determining how they are disposed to behave, and I leave open that there may be distinct such relations depending on the types of properties concerned. The step from (1) and (2) to the claim that $\psi$ is Grounded in basic physics cannot be based on the transitive closure of the specific 'in virtue of' relations expressed in (1) and (2), because they are different relations. Still, it is plausible that the conjunction of (1) and (2) entails that there is some 'in virtue of' relation between $\mathrm{H}_{2} \mathrm{O}^{\prime}$ 's having its basic physical properties and its having $\psi$, and that this relation underpins an instance of the Grounding relation discussed above. To avoid begging the question concerning the nature of this relation, let's write it as follows:

3) $\mathrm{H}_{2} \mathrm{O}$ has $\psi$ in-virtue-of ${ }_{G R}$ its basic physical properties

When I say that $\mathrm{H}_{2} \mathrm{O}$ has $\psi$ solely in virtue of $G$, I mean that it's solely in-virtueof $_{C P}$ its having $\mathrm{G}$ that $\mathrm{H}_{2} \mathrm{O}$ has $\psi$. The fact that it's in-virtue-of $\mathrm{f}_{G R}$ its basic physical properties that $\mathrm{H}_{2} \mathrm{O}$ has $\psi$ refutes this claim if, and only if, this instance of 'invirtue-of ${ }_{G R}$ ' is also an instance of 'in-virtue-of ${ }_{C P}$ '. If $\mathrm{G}$ were functionally realized, we would have independent reason to say that (3) expressed an instance of 'invirtue-of ${ }_{C P}$. As we've seen, functional properties are at most weakly emergent, so any conditional powers $\mathrm{H}_{2} \mathrm{O}$ has in-virtue-of ${ }_{C P}$ its functional properties are indeed powers it has in-virtue-of ${ }_{C P}$ its basic physical properties. ${ }^{38}$ However, $\mathrm{G}$ is not functionally realized, so this line of argument doesn't work. It's difficult to see what else one could say in favour of the claim that (3) expresses an 'in-virtueof $_{C P} P^{\prime}$ relation.

Furthermore, there are good reasons to deny that (3) expresses an instance of

38. In Yates (2012), I argue that despite not bestowing novel powers, functional properties can still do novel causal work in the sense that the functional properties of components ground the causal powers of complex mechanisms from a unique distance in a grounding hierarchy extending from basic physics upwards. However, it's functional realization all the way up, on the account proposed, so all the causal powers of mechanisms are ultimately bestowed by the basic physical properties of their components. I defend a layered ontology in Yates (2012) only insofar as I offer a rebuttal of the causal exclusion argument against it, according to which functional properties should be eliminated because there's no causal work for them to do within such an ontology. Assuming a layered model ordered by functional realization, I reply that functional properties get to be causally novel within it by means of the layer they occupy. In the present work, by contrast, I offer positive arguments for the layered model. 
'in-virtue-of ${ }_{C P}$ '. Let's remind ourselves what is at stake. To claim that the $\mathrm{H}_{2} \mathrm{O}$ molecule's basic physical properties do not bestow $\psi$ upon it amounts to denying that they are wholly causally responsible for its being disposed to align in an electric field. If $\mathrm{H}_{2} \mathrm{O}^{\prime} \mathrm{s}$ basic physical properties were wholly responsible for this fact, then we would expect to find a purely basic physical explanation thereof. However, as I argued in Section 4, no such explanation is possible. By contrast, it's easy to explain why $\mathrm{H}_{2} \mathrm{O}$ molecules are so disposed if we appeal to their geometry together with their basic physical properties, which is exactly what we would expect if the metaphysical structure of the situation were as I have described it.

In sum, there's no reason to think that (3) expresses a causal power bestowal relation, and every reason to think that it doesn't. Wilson argues that the claim that the mental is Grounded in the physical leaves open a range of specific mentalphysical relations - functional realization and type identity, for instance-and that Grounding is therefore of no use in understanding the mind-brain relationship. For that, we need to know which specific relation obtains (Wilson 2014). 39 If I am correct, then the claim that all causal powers are Grounded in basic physics leaves open whether any dependent properties are causally fundamental. I don't take this to show that Grounding is of no theoretical use, but it's certainly a failure to capture metaphysical structure.

\section{Conclusion}

Brian McLaughlin (1992) argues that the decline of British emergentism was due to the explanation of the chemical bond in quantum mechanical terms. What had seemed, to Broad, to be special chemical forces holding atoms together turned out to be an artefact of the incompleteness of the physics of the day. McLaughlin may be right about Broad, but that's no reason to give up on emergentism as a model for the autonomy of chemistry. The qualitative realization of geometric properties allows molecules to have their molecular geometry in virtue of their basic physical properties, as McLaughlin contends, and yet to have certain causal powers solely in virtue of that geometry (when 'in virtue of' is appropriately disambiguated, as discussed in Section 5). I have argued in this paper that the $\mathrm{H}_{2} \mathrm{O}$ molecule has certain conditional powers solely in virtue of its geometry, because geometry plays a unique and irreducible role in determining its dipole moment. Molecular geometry is both dependent and causally fundamental, and that's what it is for a property to be strongly emergent.

39. Wilson also argues that not being Grounded in basic physics fails to distinguish traditional strong emergentism with brute determination, in which the emergent properties are dependent upon physical base properties, from versions of property dualism that posit no such dependency on the physical. 
The reader may worry that my arguments lack broad enough application to explain the autonomy of the special sciences in full generality. I have argued only that the geometry of the $\mathrm{H}_{2} \mathrm{O}$ molecule plays a crucial role in explaining its dispositions. How does that extend to other special sciences? Molecular geometry can be seen as a kind of spatial pattern - the pattern atoms make in three dimensional space, when combined into molecules. The special sciences are replete with pattern-like properties, and not all such properties are spatial. For example, in neuroscience, temporal patterns are highly important. It has been suggested that neuronal coherence-synchronous oscillation in the sub-threshold membrane potential-increases the efficiency of neuronal communication (Fries 2005). In short, this is because the sub-threshold membrane potential represents the excitability of a neuron, so synchronously oscillating neurons share excitability peaks. This in turn means that provided the travel time of an action potential is significantly less than the period of oscillation, neurons in synchronously oscillating populations are most sensitive to inputs from neighbouring neurons just when those neurons are most likely to send action potentials..$^{\circ}$ It's not the specific oscillation rates that are doing the explanatory work here, but the pattern of phase-locked oscillation between them, and that is a multiply realizable temporal pattern akin to molecular geometry. ${ }^{41}$ Neuronal coherence is plausibly another case of a causally fundamental qualitatively realized property.

According to received wisdom, physical realization precludes strong emergence. Only spooky emergent properties get to be both dependent on basic physics and causally fundamental, and all else being equal, we shouldn't believe in those. Qualitative realization makes room for causally fundamental dependent properties without the mystery of traditional emergentism. The price of a robustly layered ontology is not physical acceptability, but functional realization. I don't deny that some special science properties are functionally realized, but I doubt that weakly emergent properties are causally novel enough to secure the autonomy of the special sciences. At least some special science properties, however, are qualitatively realized, and at least some such properties are strongly emergent. The theory developed here extends in a natural way to special sci-

40. It has also been suggested that synchronous oscillation might explain how the brain accomplishes feature binding across different sensory modalities, and there is a huge literature on this issue. I appeal to the potential role of phase-locking in explaining inter-neuronal communication here because it seems to me a clearer case of the potential causal novelty of temporal patterns in cognitive neuroscience, and because the temporal binding hypothesis is hugely controversial. See Shadlen and Movshon (1999), and the other papers in the same issue.

41. Here is Fries: "I hypothesize that [effective neuronal communication] is mechanistically implemented by the pattern of coherence among neuronal groups, that is, the pattern of phaselocking among oscillations in the communicating neuronal groups" (2005:474). 
ences such as biology and neuroscience in which the patterns realized are at least as important as the basic physical properties that realize them. ${ }^{42}$

Contrary to philosophical orthodoxy, dependent yet causally fundamental properties don't require the mysterious brute laws or special forces that led to the decline of traditional strong emergentism as an account of the autonomy of the special sciences. The idea that such things are required to secure new powers is a symptom of the dominant functionalist account of physical realization, according to which weak emergence is an upper bound on the causal novelty of realized properties. Broadly speaking, special sciences study the causal powers of complex arrangements of physical particulars; what more natural way for them to secure autonomy than by virtue of the fact that when it comes to causality, the pattern of the arrangement is just as important as what is arranged?

\section{Acknowledgments}

Earlier versions of this paper were presented at a conference on emergence and the causal completeness of physics at the University of Durham, a conference on emergence and relational metaphysics at CFCUL, University of Lisbon, and a seminar at LanCog, University of Lisbon. Thanks to all those who participated, and to two anonymous referees for Ergo, for many useful comments and criticisms. Based on research funded by an FCT Investigator grant from the Fundação para a Ciência e a Tecnologia (IF/01736/2014).

\section{References}

Alexander, Samuel (1920). Space, Time, and Deity. Macmillan.

Armstrong, David (1997). A World of States of Affairs. Cambridge University Press. https:// doi.org/10.1017/cbo9780511583308

Barnes, Elizabeth (2012). Emergence and Fundamentality. Mind, 121(464), 873-901. https://doi.org/10.1093/mind/fztoo1

Baron, Sam and Mark Colyvan (2016). Time Enough for Explanation. Journal of Philosophy, 113(2), 61-88. https://doi.org/10.5840/jphil201611324

Bird, Alexander (2007). Nature's Metaphysics. Oxford University Press. https://doi. org/10.1093/acprof:0so/9780199227013.001.0001

42. Note too that what is true of the relationship between a given special science and basic physics may also be true of the relationship between two special sciences. The mere fact that, say, neural properties are biologically realized doesn't entail that all causal powers neural structures possess are powers bestowed by their biological properties. 
Block, Ned (1997). Anti-Reductionism Slaps Back. Noûs, 31(S11), 107-132. https://doi. org/10.1111/0029-4624.31.S11.5

Broad, Charles D. (1925). The Mind and its Place in Nature. Routledge and Kegan Paul.

Crook, Seth and Carl Gillett (2001). Why Physics Alone Cannot Define the 'Physical'. Canadian Journal of Philosophy, 31(3), 333-359. https://doi.org/10.1080/00455091.2001 .10717571

Fine, Kit (2012). 'Guide to Ground'. In Fabrice Correia and Benjamin Schneider (Eds.), Metaphysical Grounding (37-80). Cambridge University Press. https://doi.org/10.1017/ cbo9781139149136.002

Fodor, Jerry A. (1974). Special Sciences. Synthese, 28(2), 97-115. https://doi.org/10.1007/ BFoo485230

Fodor, Jerry A. (1997). Special Sciences: Still Autonomous after all these Years. Noûs, 31(S11), 149-163. https://doi.org/10.1111/0029-4624.31.S11.7

Fries, Pascal (2005). A Mechanism for Cognitive Dynamics: Neuronal Communication through Neuronal Coherence. Trends in Cognitive Sciences, 9(10), 474-480. https://doi. org/10.1016/j.tics.2005.08.011

Gillett, Carl (2002). The Dimensions of Realization: a Critique of the Standard View. Analysis, 62(276), 316-323. https://doi.org/10.1093/analys/62.4.316

Gillett, Carl (2003). The Metaphysics of Realization, Multiple Realizability and the Special Sciences. Journal of Philosophy, 100(11), 591-603.

Heil, John (2003). From an Ontological Point of View. Oxford University Press. https://doi. org/10.1093/0199259747.001.0001

Heil, John (2016). Causal Relations. In Anna Marmodoro and David Yates (Eds.), The Metaphysics of Relations (127-137). Oxford University Press. https://doi.org/10.1093/ acprof:oso/9780198735878.003.0008

Horgan, Terence (1993). From Supervenience to Superdupervenience: Meeting the Demands of a Material World. Mind, 102(408), 555-586. https://doi.org/10.1093/ mind/102.408.555

Jackson, Frank and Philip Pettit (1990). Program Explanation: a General Perspective. Analysis, 50(2), 107-117. https://doi.org/10.1093/analys/50.2.107

Kim, Jaegwon (1992). Multiple Realization and the Metaphysics of Reduction. Philosophy and Phenomenological Research, 52(1), 1-26. https://doi.org/10.2307/2107741

Kim, Jaegwon (1998). Mind in a Physical World. MIT Press.

List, Christian and Peter Menzies (2010). The Causal Autonomy of the Special Sciences. In Cynthia Macdonald and Graham Macdonald (Eds.), Emergence in Mind (108-128). Oxford University Press.

McLaughlin, Brian (1992). The Rise and Fall of British Emergentism. In Angsar Beckermann, Hans Flohr, and Jaegwon Kim (Eds.), Emergence or Reduction? Essays on the Prospects of Non-reductive Physicalism (49-93). Walter de Gruyter. https://doi. org/10.1515/9783110870084.49

Melnyk, Andrew (2003). A Physicalist Manifesto: Thoroughly Modern Materialism. Cambridge University Press. https://doi.org/10.1017/cbo9780511498817

Molnar, George (2003). Powers: A Study in Metaphysics. Oxford University Press.

Morgan, Charles L. (1923). Emergent Evolution. Williams \& Norgate.

Mumford, Stephen and Rani Lill Anjum (2011). Getting Causes From Powers. Oxford University Press. https://doi.org/10.1093/acprof:0so/9780199695614.001.0001

Papineau, David (2002). Thinking about Consciousness. Clarendon. https://doi. org/10.1093/0199243824.001.0001 
Putnam, Hilary (1975). Philosophy and Our Mental Life. In his Mind, Language and Reality: Philosophical Papers (Vol. 2, 291-303). Cambridge University Press.

Shadlen, Michael and Anthony Movshon (1999). Synchrony Unbound: A Critical Evaluation of the Temporal Binding Hypothesis. Neuron, 24(1), 67-77. https://doi. org/10.1016/So896-6273(00)80822-3

Shapiro, Lawrence A. (2000). Multiple Realizations. Journal of Philosophy, 97(12), 635-654. https://doi.org/10.2307/2678460

Shoemaker, Sydney (1980). Causality and Properties. in Peter van Inwagen (Ed.), Time and Cause (109-135). Reidel. https://doi.org/10.1007/978-94-017-3528-5_7

Shoemaker, Sydney (2001). Realization and Mental Causation. in Carl Gillett and Barry Loewer (eds.), Physicalism and its Discontents (74-98). Cambridge University Press. https://doi.org/10.1017/cbo9780511570797.005

Shoemaker, Sydney (2007). Physical Realization. Oxford University Press. https://doi. org/10.1093/acprof:0so/9780199214396.001.0001

Sperry, Roger W. (1975). Mental Phenomena as Causal Determinants in Brain Function. Process Studies, 5(4), 247-256. https://doi.org/10.5840/process19755431

Wilson, Jessica (1999). How Superduper Does a Physicalist Supervenience Need to Be? Philosophical Quarterly, 50(194), 33-52. https://doi.org/10.1111/1467-9213.00127

Wilson, Jessica (2005). Supervenience-Based Formulations of Physicalism. Nô̂s, 39(3), 426-459. https://doi.org/10.1111/j.0029-4624.2005.00508.x

Wilson, Jessica (2006). On Characterizing the Physical. Philosophical Studies, 131(1), 61-99. https://doi.org/10.1007/s11098-006-5984-8

Wilson, Jessica (2011). Non-reductive Realization and the Powers-based Subset Strategy. The Monist, 94(1), 121-154. https://doi.org/10.5840/monist20119417

Wilson, Jessica (2014). No Work for a Theory of Grounding. Inquiry, 57(5-6), 535-579. https://doi.org/10.1080/0020174X.2014.907542

Wilson, Jessica (2015). Metaphysical Emergence: Weak and Strong. In Tomasz Bigaj and Christian Wüthrich (Eds.), Metaphysics in Contemporary Physics (345-402). Poznan Studies in the Philosophy of the Sciences and the Humanities.

Yablo, Stephen (1992). Mental Causation. Philosophical Review, 101(2), 245-280. https:// doi.org/10.2307/2185535

Yates, David (2009). Emergence, Downwards Causation, and the Completeness of Physics. Philosophical Quarterly, 59(234), 110-131. https://doi.org/10.1111/j.14679213.2008.556.x

Yates, David (2012). Functionalism and the Metaphysics of Causal Exclusion. Philosophers' Imprint 12(13), 1-25. 